\title{
Neuromythology of Manganism
}

\author{
Kristin M. Andruska ${ }^{1} \cdot$ Brad A. Racette ${ }^{1,2}$
}

Published online: 7 April 2015

(C) Springer International Publishing AG 2015

\begin{abstract}
Manganese is an essential trace element with neurotoxicant properties at high levels that were first described in the mid-nineteenth century. The largest sources of occupational and environmental exposures are mining, fossil fuel combustion, and iron and steel industries. Manganese neurotoxicity has been described in many workers with high levels of occupational manganese exposure and can cause a distinct neurologic phenotype known as manganism. Recently, our understanding of the clinical syndrome and pathophysiology of manganese toxicity has shifted. Modern day manganese exposures, which are an order of magnitude lower than previously described in cases of manganism, result in different clinical, imaging, and pathologic phenotypes. Here, we will review three neurologic "myths" of manganism in the twentyfirst century and will provide evidence that $\mathrm{Mn}$ is associated with a clinical syndrome of parkinsonism that resembles Parkinson disease, dopaminergic dysfunction on molecular imaging, and an inflammatory neuropathology in the striatum.
\end{abstract}

Keywords Manganese - Manganism - Parkinson disease · Parkinsonism $\cdot$ Welding $\cdot$ Neurotoxicity

This article is part of the Topical Collection on Environmental Epidemiology

Brad A. Racette

racetteb@neuro.wustl.edu

Kristin M. Andruska

andruskak@neuro.wustl.edu

1 Department of Neurology, Washington University School of Medicine, 660 South Euclid Ave., Box 8111, St. Louis, MO 63110, USA

2 School of Public Health, Faculty of Health Sciences, University of the Witwatersrand, Parktown, Johannesburg, South Africa

\section{Introduction}

Carl Wilhelm Scheele, a Swedish pharmaceutical chemist, is credited with discovering manganese (Mn) in the eighteenth century [1]. Manganese (Mn) is present in trace elemental concentrations in the human body and is required for metabolism. Mn can enter the body through inhalation or ingestion. Ingested manganese is processed through the hepatobiliary system. The fraction of Mn not required for enzyme metabolism undergoes first-pass metabolism and is excreted in bile through the gastrointestinal tract. When $\mathrm{Mn}$ is present in airborne particulate matter, large insoluble particles are cleared from the upper airways by mucociliary transport. However, inhaled Mn that penetrates deep into the lungs is absorbed by macrophages and transported into the systemic circulation, thereby escaping first-pass metabolism. In this way, $\mathrm{Mn}$ is taken up into the bloodstream and easily crosses the bloodbrain barrier [2]. In addition to Mn mining, the bulk of environmental and industrial Mn exposures comes from welding, steel production, and fossil fuel combustion. Manganese is naturally found in coal and is released in coal-fired power plants. It is also released in combustion engines using the gasoline additive methylcyclopentadienyl manganese tricarbonyl (MMT), which is permitted in countries worldwide, including the USA, Canada, China, and the European Union. As a result of these and other industrial exposures, billions of people in developed and newly industrialized countries are routinely exposed to environmental $\mathrm{Mn}$.

At very high concentrations, especially those in industrial settings, inhaled Mn can produce a fulminant neurologic syndrome, known as manganism. The first clinical description of Mn neurotoxicity dates back to 1837 , when James Couper [3] described Scottish industrial workers exposed to manganese oxide who developed gait disorder, tremor, whispering speech, and masked facies. The clinical syndrome of 
manganism is largely congruent with parkinsonism and has subsequently been described in several populations exposed to manganese, including Moroccan ore workers [4], English factory workers [5], Chilean miners [6], and Taiwanese laborers [7]. For the most part, these workers were exposed to Mn concentrations that are orders of magnitude greater than contemporary environmental and occupational exposures. As a result, studies in workers exposed in the twenty-first century demonstrate different clinical, imaging, and pathological phenotypes. This review will focus on three key "myths" about manganism and discuss gaps in knowledge to be addressed in future studies.

\section{Myth No. 1: The Features of Manganese-Induced Parkinsonism Are Easily Distinguishable from Other Causes of Parkinsonism}

Parkinsonism is a clinical syndrome characterized by bradykinesia, postural instability, rest tremor, and rigidity. The most common degenerative parkinsonism is Parkinson disease (PD), a progressive condition that affects approximately $2 \%$ of people over age 65 [8]. PD is associated with degeneration of substantia nigra and intraneuronal deposition of alpha synuclein (either Lewy bodies or Lewy neurites) and clinical improvement of symptoms with the dopamine precursor levodopa. Parkinsonism is also commonly seen with aging [9]. Age-related parkinsonism is associated with functional disability [10] and may serve as a marker for degenerative brain pathologies. Numerous studies demonstrate that parkinsonism is an important clinical feature of Mn neurotoxicity. Since Couper [3] described the first cases of parkinsonism among Mn ore crushers, many authors have identified other groups of occupationally exposed workers with similar syndromes. In Rodier's description of Moroccan miners, he expanded the description to include "manganese psychosis," characterized by aggression, mental excitement, and incoherent speech [4]. Many authors have described the extrapyramidal symptoms that Rodier first associated with Mn exposure [7, 11-14]. Some aspects of this clinical phenotype have been seen in other Mn over-exposure settings such as smelter workers and ephedrone abusers [7, 15]. Some authors have considered the "cock walk" to be a clinical sign that is specific to $\mathrm{Mn}$ neurotoxicity $[14,16]$.

This phenotype appears to be uncommon with Mn exposure at modern levels. Numerous studies demonstrate motor slowing and tremor, without evidence of other neurologic dysfunction, in Mn-exposed workers [17-19]. None of these studies included systematic examination by a clinical expert. We conducted a worksite-based study comparing the phenotype of 716 welders to that of non-welder controls and found a high prevalence of parkinsonism (15.6\%) in manganeseexposed welders. Their symptom severity, specifically bradykinesia and rigidity, were comparable to those with newly diagnosed PD. Furthermore, affected welders had a Ushaped Mn dose-response relationship between welding exposure and parkinsonism, as defined by Unified Parkinson Disease Rating Scale motor subsection 3 (UPDRS3) $\geq 15$ (Table 1). Subjects with preexisting neurologic disease were excluded, and the welding population was relatively young (mean age 45), suggesting that parkinsonism was likely related to occupational Mn inhalation [20••]. These parkinsonian signs appear to be associated with reductions in PD-specific quality of life measures [21], suggesting that these neurologic signs impact daily function in Mn-exposed welders. The clinical features of these subjects were very similar to those in a previous study investigating the prevalence of parkinsonism in Mn-exposed welders [22]. Interestingly, in over $4000 \mathrm{Mn}$ exposed workers evaluated across numerous studies, we have not found any subject with a "cock gait." These differences may highlight the dichotomy between low-level Mn exposure (welders who are exposed to inhaled Mn-containing fume or dust) and more substantial exposures (miners who crush $\mathrm{Mn}$ ore and those who worked in historic occupational conditions). We hypothesize that low-level Mn exposure over time may more accurately mimic environmental triggers that have been associated with PD risk [8].

While it is clear that very high doses of Mn are associated with subacute onset of severe neurologic dysfunction, it is becoming increasingly clear that there is a spectrum of neurologic effects associated with chronic, lower Mn exposures. It is critical to identify the threshold for symptomatic exposure to inform regulatory policy. While the Moroccan miners described by Rodier were exposed to Mn levels up to 926, $000 \mu \mathrm{g} / \mathrm{m}^{3}$ [4], current occupational welding exposures are several orders of magnitude less [23-25]. The limit set by the US Occupational Safety and Health Administration for

Table 1 Prevalence ratios (PRs) for parkinsonism in relation to total welding exposure-years (Adapted from Racette et al., Neurotoxicology, $[20 \bullet \bullet])$

\begin{tabular}{lll}
\hline & PR $(95 \% \mathrm{CI})^{\mathrm{a}}$ & PR $(95 \% \mathrm{CI})^{\mathrm{b}}$ \\
& UPDRS3 & UPDRS3 \\
& $\geq 15$ vs. $<6$ & $\geq 15$ vs. $<6$ \\
\multicolumn{2}{l}{ Total weighted welding exposure-years } \\
$<1.0$ & Reference & \\
$1.0-3.4$ & $1.7(0.9-2.9)$ & Reference \\
$3.4-8.8$ & $2.0(1.2-3.4)$ & $1.4(0.8-2.4)$ \\
$\geq 8.8$ & $1.8(1.0-3.1)$ & $1.4(0.9-2.3)$ \\
$p$ trend & & $1.0(0.6-1.6)$ \\
\hline
\end{tabular}

${ }^{\text {a }}$ Crude estimates

${ }^{\mathrm{b}}$ Adjusted for age at examination, gender, examining neurologist, and days since last occupational welding exposure; analyses restricted to workers from welding worksites

${ }^{\mathrm{c}}$ Weighted by job category and title 
Mn permissible exposure is $5 \mathrm{mg} / \mathrm{m}^{3}$, calculated as a timeweighted average (TWA) for $8 \mathrm{~h}$, whereas the National Institute for Occupational Safety and Health's recommended exposure limit is $1 \mathrm{mg} / \mathrm{m}^{3}$ [25]. Recently, the American Conference of Governmental Industrial Hygienists (ACGIH) set the 8-h TWA Mn inhalable threshold limit value at $0.1 \mathrm{mg} / \mathrm{m}^{3}$, citing impaired motor function, impaired steadiness, tremor, and behavioral and cognitive dysfunction at exposures as low as $13 \mu \mathrm{g} / \mathrm{m}^{3}[17,26 \bullet, 27]$. In fact, even low-level environmental $\mathrm{Mn}$ exposures are associated with motor and cognitive dysfunction. In a community-based study, which excluded subjects exposed to occupational $\mathrm{Mn}$, those with higher serum Mn levels had significantly worse tremor, rapid alternating movements, coordination, and memory [28]. Taken together, these data suggest that Mn neurotoxicity occurs on a spectrum. The finding that even low-level exposures are associated with parkinsonism has important implications for workplace safety and policy as we continue to define the effects of longterm Mn exposure and acceptable occupational thresholds.

\section{Myth No. 2: Manganese Neurotoxicity Is Distinguishable from PD by Normal Dopaminergic Function on Molecular Imaging of the Striatum}

Several imaging studies have focused on identifying nigrostriatal dysfunction in manganese-induced neurotoxicity. Methods such as single-photon emission computed tomography (SPECT) and positron emission tomography (PET) studies use radioligands to quantify dopaminergic function by labeling enzymes responsible for synthesis, vesicular transport, or reuptake. Three common radioligands include $\left[{ }^{18} \mathrm{~F}\right]$ flurodopa (FDOPA), vesicular monoamine transporter 2 (VMAT2), and dopamine transporter (DAT). FDOPA labels the enzyme responsible for converting L-DOPA to dopamine [29]. VMAT2 transports monoamines into presynaptic vesicles [30]. DAT catalyzes dopamine reuptake into presynaptic terminals [31].

The first studies to investigate the dopaminergic system in subjects with symptomatic manganism found normal FDOPA uptake in the striatum in four workers [32]. Similarly, SPECT studies using a DAT-labeled radioligand in four patients with chronic manganese-ephedrone exposure found no evidence of dopaminergic dysfunction [33]. One challenge with interpreting negative SPECT studies, and to a certain extent older PET studies, is the lower resolution compared to contemporary PET scanners, which makes segmenting the striatum to obtain region-specific binding potentials $\left(K_{\mathrm{i}} \mathrm{s}\right)$ difficult. Furthermore, studies in older populations can be confounded by coincident PD [34], and nearly all studies have been limited by very small sample sizes.

In a more recent FDOPA PET study, presymptomatic Mn workers were compared to patients with idiopathic PD and unaffected controls [35]. The study design included 20 young, manganese-exposed welders without a known family history of parkinsonism to mitigate the possibility that the results would be confounded by co-occurring idiopathic PD. The results demonstrated significantly lower FDOPA uptake in the striatum of asymptomatic Mn welders compared to nonparkinsonian controls. The FDOPA uptake was lower in the caudate compared to the putamen in the Mn welders. Interestingly, patients with PD exhibit the reverse pattern: comparatively less FDOPA uptake in the putamen as compared to the caudate. While patients with Mn exposure and PD both demonstrate nigrostriatal toxicity, it remains unclear if this pattern is pathognomonic for $\mathrm{Mn}$ neurotoxicity, since these workers had relatively few motor signs of parkinsonism. In contrast, we have performed FDOPA PET on two patients with Mn neurotoxicity due to liver failure $[36,37 \bullet \bullet]$. These subjects had more severe parkinsonian signs, and both had more dopaminergic dysfunction in the putamen than Mn-exposed welders. This suggests that $\mathrm{Mn}$ neurotoxicity with parkinsonism has an FDOPA PET pattern that is more typical of PD. Confirming this finding in Mn-exposed workers with higher UPDRS3 scores is essential.

\section{Myth No. 3: Neuropathology of Manganese Neurotoxicity Is Well-Described and Unique from PD}

Until recently, evidence describing the neuropathology of manganism has been limited to several case reports and series. The earliest detailed histopathological case report of manganism toxicity was written in 1927. In his case report of a Mn dioxide grinder, Ashizawa describes the marked loss of ganglion cells in the gray matter, specifically the pallidum, caudate, and putamen [38]. Seven years later, Canavan and colleagues published a case series of manganese-exposed patients with easily recognizable tremor, masked facies, hypophonia, retropulsion, propulsion, and steppage gait. One of these manganese-exposed mill workers was examined serially over 10 years, and then autopsied at death, revealing substantial basal ganglia neurodegeneration with marked gliosis and focal caudate and globus pallidus scarring [39]. During the first half of the twentieth century, several others described similar neuropathology in those with manganism [40-42]. Since then, Yamada and Bernheimer reported patients with Mn exposure history whose autopsies also demonstrate marked pallidum degeneration [43, 44]. While these descriptive reports help elucidate the pathophysiology of $\mathrm{Mn}$ neurotoxicity, they were performed before modern immunohistochemical techniques; all cases were of end-stage disease, and most lacked quantification of cell types. Only one case was compared to a reference brain [43]. 
Recently, Gonzalez-Cuyar et al. conducted a controlled, quantitative neuropathologic study of eight $\mathrm{Mn}$ and eight non-Mn-exposed South African mine workers. Subjects in these mines were asymptomatic at the time of autopsy, carefully matched to controls, and exposed to low-level Mn. The average South African mine exposure ( $8 \mathrm{~h}$ TWA) is estimated at 190 to $780 \mu \mathrm{g} / \mathrm{m}^{3}$, with average exposure equal to $210 \mu \mathrm{g} /$ $\mathrm{m}^{3}$ [23]. The average age at death was 57 for Mn mine workers and 60 for matched controls. Interestingly, at autopsy, the manganese-exposed group had significantly lower astrocyte to microglia ratio in the caudate ( 7.80 for $\mathrm{Mn}$ mine workers and 14.68 for non-Mn mine workers, $p=0.025$ ) and a trend toward higher microglial density ( $52 \%$ higher in globus pallidus externa and $38 \%$ higher in globus pallidus interna), lower astrocyte density (19\% for both caudate and putamen), and lower neuron density (14 and $8 \%$ for caudate and putamen, respectively) [45••]. Astrocyte vulnerability to Mn may be related to high-affinity metal transporter expression, leading to intracellular $\mathrm{Mn}$ accumulation, subsequent reactive oxygen species formation, and downstream inflammation [46]. The mechanism of upstream dysfunction leading to neuronal death has also been proposed for neurodegenerative diseases, including the "dying back" phenomenon of PD pathology $[47,48]$. These results suggest that manganeseinduced neurodegeneration may initially lead to a microglial infiltration in the basal ganglia followed by damage to astrocytes, which ultimately leads to neuronal loss, since a critical function of astrocytes is to support and repair neurons. If proven in future neuropathology studies, this may provide therapeutic and neuroprotective pathways to protect workers and those with environmental exposures.

\section{Conclusions}

The data on Mn exposure to date provide a compelling link between Mn exposure and parkinsonism. Largely unregulated exposures in the eighteenth and early nineteenth centuries produced a clinical syndrome that is rare in modern times. In contrast, contemporary Mn exposures appear to be associated with parkinsonism, cognitive dysfunction, as well as associated dopaminergic dysfunction and possible pathologic accumulation of microglia in the basal ganglia. These occupational studies as well as recent environmental studies [49, 50] suggest that regulatory limits for $\mathrm{Mn}$ exposure should be revisited. Permissible US ambient air Mn concentrations have been determined by extrapolating from occupational health studies $[4,51,52]$, and these have not been revised for more than two decades. Future studies with longitudinal clinical and exposure data in occupationally and environmentally exposed subjects should guide occupational policy. Advanced imaging and biologic measurements should augment these studies and provide a biologic framework to understand disease mechanism to guide therapeutic strategies. Finally, studies attempting to link neurodegenerative diseases, such as PD, and aging-related motor and cognitive dysfunction to Mn exposures should be the ultimate goal.

\section{Compliance with Ethics Guidelines}

Conflict of Interest KM Andruska declares no conflicts of interest. BA Racette has received research grants from the National Institute for Environmental Health Sciences during the conduct of the study.

Human and Animal Rights and Informed Consent All studies by BA Racette involving animal and/or human subjects were performed after approval by the appropriate institutional review boards. When required, written informed consent was obtained from all participants.

\section{References}

Papers of particular interest, published recently, have been highlighted as:

- Of importance

•- Of major importance

1. Scheele C. On manganese, or magnesia, and its properties. Proc R Sci Acad Sweden. 1774;35:89-116.

2. Costa LG, Aschner M, editors. Manganese in health and disease. Cambridge: The Royal Society of Chemistry; 2014. $632 p$.

3. Couper J. On the effects of black oxide of manganese when inhaled into the lungs. Br Ann Med Pharm. 1837;1:41-2.

4. Rodier J. Manganese poisoning in Moroccan miners. Br J Ind Med. 1955;12(1):21-35.

5. Charles JR. Short notes and clinical cases: three cases of manganese poisoning. J Neurol Psychopathol. 1922;3(11):262-8.

6. Mena I, Marin O, Fuenzalida S, Cotzias GC. Chronic manganese poisoning: clinical picture and manganese turnover. Neurology. 1967;17(2):128

7. Wang JD, Huang CC, Hwang YH, Chiang JR, Lin JM, Chen JS. Manganese induced parkinsonism: an outbreak due to an unrepaired ventilation control system in a ferromanganese smelter. Occup Environ Med. 1989;46(12):856-9.

8. Wright Willis A, Evanoff BA, Lian M, Criswell SR, Racette BA. Geographic and ethnic variation in Parkinson disease: a populationbased study of US Medicare beneficiaries. Neuroepidemiology. 2010;34(3):143-51.

9. Louis ED, Luchsinger JA, Tang MX, Mayeux R. Parkinsonian signs in older people: prevalence and associations with smoking and coffee. Neurology. 2003;61(1):24-8.

10. Louis ED, Tang MX, Schupf N, Mayeux R. Functional correlates and prevalence of mild Parkinsonian signs in a community population of older people. Arch Neurol. 2005;62(2):297-302.

11. Huang C, Chu N, Lu C. Chronic manganese intoxication. Arch Neurol. 1989;30:59-64.

12. Whitlock C, Amuso S, Bittenbender J. Chronic neurological disease in two manganese steel workers. Am Ind Hyg Assoc J. 1966;27:454-9.

13. Lu C, Huang $\mathrm{C}, \mathrm{Chu} \mathrm{N}$, Calne D. Levodopa failure in chronic manganism. Neurology. 1994;44(9):1600-2. 
14. Calne D, Chu N, Huang C, Lu C, Olanow W. Manganism and idiopathic parkinsonism: similarities and differences. Neurology. 1994;44(9):1583-6.

15. De Bie R, Gladstone RM, Strafella AP, Ko J, Lang AE. Manganeseinduced parkinsonism associated with methcathinone (Ephedrone) abuse. Arch Neurol. 2007;64(6):886-9.

16. Jankovic J. Searching for a relationship between manganese and welding and Parkinson's disease. Neurology. 2005;64(12):2021-8.

17. Roels H, Sarhan M, Hanotiau I, de Fays M, Genet P, Bernard A, et al. Preclinical toxic effects of manganese in workers from a Mn salts and oxides producing plant. Sci Total Environ. 1985;42:201-6.

18. Lucchini R, Apostoli P, Perrone C, Placidi D, Albini E, Migliorati P, et al. Long-term exposure to "low levels" of manganese oxides and neurofunctional changes in ferroalloy workers. Neurotoxicology. 1999;20(2-3):287-97.

19. Lucchini R, Bergamaschi E, Smargiassi A, Festa D, Apostoli P. Motor function, olfactory threshold, and hematological indices in manganese-exposed ferroalloy workers. Environ Res. 1997;73(1-2): 175-80.

20.• Racette BA, Criswell SR, Lundin JI, Hobson A, Seixas N, Kotzbauer PT, et al. Increased risk of parkinsonism associated with welding exposure. Neurotoxicology. Elsevier B.V.2012;33(5): 1356-61. This occupational study of manganese exposed welders demonstrates a high prevalence of parkinsonism compared to nonwelders and a clinical phenotype that overlaps substantially with PD.

21. Harris RC, Lundin JI, Criswell SR, Swisher LM, Evanoff BA, Racette BA. Effects of parkinsonism on health status in welding exposed workers. Parkinsonism Relat Disord. 2011;17(9):672-6.

22. Racette BA, Tabbal SD, Jennings D, Good L, Perlmutter JS, Evanoff B. Prevalence of parkinsonism and relationship to exposure in a large sample of Alabama welders. Neurology. 2005;64(2): 230-5.

23. Ruhf R. Control of manganese dust and fume exposures at a ferromanganese production and processing facility. J Occup Med. 1978;20(9):626-8.

24. Meeker J, Susi P, Flynn M. Manganese and welding fume exposure and control in construction. J Occup Environ Hyg. 2007;4(12): 943-51.

25. Manganese fume. Available from: https://www.osha.gov/dts/ chemicalsampling/data/CH_250200.html.

26. Laohaudomchok W, Lin X, Herrick RF, Shona C, Cavallari JM, Shrairman R, et al. Neuropsychological effects of low-level manganese exposure in welders. Neurotoxicology. 2012;32(2):171-9

In contrast to the previously described symptoms of high level Mn exposure, this study demonstrates that low level Mn exposure manifests the neuropsychological symptoms of decreased attention, mood, and fine motor control.

27. American Conference of Governmental Industrial Hygienists. Documentation of the threshold limit values (TLVs) and biological exposure indices (BEIs) - manganese, elemental and inorganic compounds. 2013.

28. Mergler D, Baldwin M, Bélanger S, Larribe F, Beuter A, Bowler R, et al. Manganese neurotoxicity, a continuum of dysfunction: results from a community based study. Neurotoxicology. 1999;20(2-3): 327-42.

29. Martin W, Perlmutter J. Assessment of fetal tissue transplantation in Parkinson's disease: does PET play a role? Neurology. 1994;44(10):1777-80.

30. Henry J, Scherman D. Radioligands of the vesicular monoamine transporter and their use as markers of monoamine storage vesicles. Biochem Pharmacol. 1989;38(15):2395-404.

31. Kim J, Kim J-M, Kim YK, Shin JW, Choi SH, Kim SE, et al. Dopamine transporter SPECT of a liver cirrhotic with atypical Parkinsonism. Ind Health. 2007;45(3):497-500.
32. Wolters EC, Huang CC, Clark C, Peppard RF, Okada J, Chu NS, et al. Positron emission tomography in manganese intoxication. Ann Neurol. 1989;26(5):647-51.

33. Sikk K, Taba P, Haldre S, Bergquist J, Nyholm D, Askmark H, et al. Clinical, neuroimaging and neurophysiological features in addicts with manganese-ephedrone exposure. Acta Neurol Scand. 2010;121(4):237-43.

34. Kim Y, Kim J, Ito K, Lim H, Cheong H, Kim J, et al. Idiopathic parkinsonism with superimposed manganese exposure: utility of positron emission tomography. Neurotoxicology. 1999;20(2-3): 249-52.

35. Criswell SR, Perlmutter JS, Videen TO, Moerlein SM, Flores HP, Birke AM, et al. Reduced uptake of [18F] FDOPA PET in asymptomatic welders with occupational manganese exposure. Neurology. 2011;76(15):1296-301.

36. Racette BA, Antenor JA, McGee-Minnich L, Moerlein SM, Videen TO, Kotagal V, et al. [18F]FDOPA PET and clinical features in parkinsonism due to manganism. Mov Disord. 2005;20(4):492-6.

37.• Criswell S, Perlmutter J, Crippin J, Videen T, Moerlein S, Flores H, et al. Reduced uptake of $\left[{ }^{18} \mathrm{~F}\right] \mathrm{FDOPA}$ PET in end-stage liver disease with elevated manganese levels. Arch Neurol. 2012;69(3): 394-7. This study was the first study to demonstrate a specific pattern of dopaminergic dysfunction in Mn-exposed workers.

38. Ashizawa R. Uber einen sektionsfall von chronischer manganvergiftung. Jap J Med Sci Trans Sect VIII-Int Med Pediat Psychait. 1927;(1):173-91.

39. Canavan M, Cobb S, Drinker C. Chronic manganese poisoning: report of a case with autopsy. Arch Neurol Psychiatr. 1934;52: 501-12.

40. Gayle RFJ. Manganese poisoning and its effect on the central nervous system. JAMA. 1925;85(26):2008-11.

41. Stadler H. Zur histopathologie des gehims bei manganvergiftung. Z Gesamte Neurol Psychiatr. 1936;154:62-76.

42. Trendtel F. Zur frage des manganismus. Mschr Unfallheilk. 1936;43:69-84.

43. Yamada M, Ohno S, Okayasu I, Okeda R, Hatakeyama S, Watanabe $\mathrm{H}$, et al. Chronic manganese poisoning: a neuropathological study with determination of manganese distribution in the brain. Acta Neuropathol. 1986;70(3-4):273-8.

44. Bernheimer H, Birkmayer W, Hornykiewicz O, Jellinger K, Seitelberger F. Brain dopamine and the syndromes of Parkinson and Huntington. Clinical, morphological and neurochemical correlations. J Neurol Sci. 1973;20(4):415-55.

45.• Gonzalez-Cuyar LF, Nelson G, Criswell SR, Ho P, Lonzanida JA, Checkoway H, et al. Quantitative neuropathology associated with chronic manganese exposure in South African mine workers. Neurotoxicology. 2014;45:260-6

This study compares the neuropathology of preclinical Mn exposed workers to unexposed controls and demonstrates pathologic changes in the caudate, putamen, and globus pallidus of Mn exposed workers.

46. Filipov N, Dodd C. Role of glial cells in manganese toxicity. J Appl Toxicol. 2012;32(5):310-7.

47. Galvin JE, Uryu K, Lee VM, Trojanowski JQ. Axon pathology in Parkinson's disease and Lewy body dementia hippocampus contains alpha-, beta-, and gamma-synuclein. Proc Natl Acad Sci. 1999;96(23):13450-5.

48. Choi W-S, Palmiter RD, Xia Z. Loss of mitochondrial complex I activity potentiates dopamine neuron death induced by microtubule dysfunction in a Parkinson's disease model. J Cell Biol. 2011;192(5):873-82.

49. Willis AW, Evanoff BA, Lian M, Galarza A, Wegrzyn A, Schootman M, et al. Metal emissions and urban incident Parkinson disease: a community health study of Medicare beneficiaries by using geographic information systems. Am J Epidemiol. 2010;172(12):1357-63. 
50. Lucchini RG, Albini E, Benedetti L, Borghesi S, Coccaglio R, Malara EC, et al. High prevalence of Parkinsonian disorders associated to manganese exposure in the vicinities of ferroalloy industries. Am J Ind Med. 2007;50(11):788-800.

51. Roels H, Lauwerys R, Buchet JP, Genet P, Sarhan MJ, Hanotiau I, et al. Epidemiological survey among workers exposed to manganese: effects on lung, central nervous system, and some biological indices. Am J Ind Med. 1987;12(1):119-20.

52. Roels H, Ghyselen P, Buchet JP, Ceulemans E, Lauwerys RR. Assessment of the permissible exposure level to manganese in workers exposed to manganese dioxide dust. Occup Environ Med. 1992;49(1):25-34. 